\title{
Information Management and Green Construction Evaluation
}

\author{
Yun Liu ${ }^{1, a}$, Yu Xiao ${ }^{1, b}$ and Yunchao Zhang ${ }^{2, c}$ \\ ${ }^{1}$ College of Civil Engineering, Tongji University, Shanghai 200092, China \\ ${ }^{2}$ Shanghai Construction No.4(Group)Co., LTD, Shanghai 200092, China \\ a93427@tongji.edu.cn, ${ }^{\mathrm{b}}$ xiaoyu@tongji.edu.cn, ${ }^{\mathrm{c}}$ lushanlaoren@163.com
}

\begin{abstract}
Keywords: green construction evaluation; information management; evaluation index
Abstract. The construction phase plays an important role in the project life cycle, consuming a lot of natural resources. The development of green construction is significant to develop sustainably by saving natural resource and protecting the environment, and its evaluation makes it possible to implement the sustainable development in the construction industry. By the analysis and decomposition of Guidance for Green Construction, Evaluation Standard for Green Construction of Building and Technical Index for Green Construction of Technological Demonstration Project, the differences and connections between the evaluation indexes were studied. In the research of green construction evaluation, a database-based information exchange model was proposed to improve green construction management by applying coding technology, using and storing BIM's data.
\end{abstract}

\section{Introduction}

With the high development of the construction industry, the living environment has been improved and the employment pressure has been alleviated. The construction industry, characterized by high investment growth, high consumption support and high emission maintenance, has caused huge pollution of environment. In the process, $45 \%$ cement and more than $50 \%$ steels and energies are used. And the number of construction waste accounts for $30 \%$ to $40 \%$ amount that of municipal waste. Green construction is an important way to give impetus to industrial transformation and upgrading.

Green construction can be defined in a broad and narrow sense. In this broad sense, green construction is the key to achieving green building and sustainable development in the whole project life cycle: from site selection, design, construction, operation to demolition [1]; in a narrower sense, green construction is a construction activity to strike a balance between maintaining firm control of the quality, safety and other basic requirements and saving resources. It could reduce the negative impact on the environment by scientific management and high technology to realize "four conversations and one protection", energy-saving, land-saving, water-saving, material-saving and environment-protecting [2,3]. With the development of society, new requirements such as saving labor resources, selecting machinery and building information platform are put forward and green construction emerges.

Xiaohong Chen [4] identified the $\mathrm{M}$ and $\mathrm{L}$ evaluation indicators and criterion, confirmed the weight of each indicator through Analytic Hierarchy Process (AHP) and established the evaluation model. Wanqing Li et al. [5] summarized the evaluation model according to AHP and fuzzy set theory. And they advanced an improved transformation algorithm for membership degree to identify the redundant indices' membership degree and the redundant figures in the index subjection which do not work for the target's classification. Huiling Li et al. [6] used gray poly class evaluation method and established the model based on cluster and vector to evaluate the construction project by analysing and calculating the weight of the green construction's evaluation index and triangle whiten value. Zaixing Liu [7] evaluated the green construction objectively based on fuzzy evaluation matrix and BP artificial neural network in processing data. Yingpan Li et al. [8] combined BIM with Cloud Computing and set up the framework of green construction management based on Cloud-BIM technology platform. Many scholars at home and abroad has built green construction evaluation index systems and models from different aspects and different methods. However, they do not consider the existing construction evaluation codes and do not take the differences and indifferences between 
different codes into consideration. Thus, they cannot be directly used in the actual construction evaluation activities.

With an analysis of the existing construction evaluation of the codes in China and sorting out the norms and provisions, this paper establishes the construction evaluation system and raises the information exchange model based on the database by the coding technology. And a construction evaluation of a process can be output different results to meet rules in evaluation codes.

\section{Status of Green Construction Evaluation}

In 1990, the British Institute of Architecture proposed the first green building evaluation system recognized by the world, Building Research Assessment Method (BREEAM) [9], the issue of BREEAM helps many countries to formulate green building assessment system.

In 1995, the US Green Building Council founded the Leadership in Energy and Environmental Design (LEED) [10]. In addition, the emerge of GBC in Canada, Green Calc+ in Netherlands, NABERS in Australia, LNB in Germany, ESCALE in France, Eco Profile in Norway, KGBC in South Korea and CASBEE in Japan, enriched the green building evaluation system [11].

The evaluation mainly focused on green buildings in foreign countries appeared earlier, but hardly on green construction. What's more, the green buildings' evaluation is simple or results-oriented.

Since 1990s, with the introduction of the idea about green building, China will also concentrate on Green Building and Green Construction and has promulgated Guidance for Guidance for Green Construction [2], Evaluation Standard for Green Construction of Building [3], Technical Index for Green Construction of Technological Demonstration Project [12] and other national guidance documents, standards, and local civilized construction codes. Compared to foreign norms, the Chinese norms which have Chinese characteristics have detailed terms on green construction.

Guidance for Green Construction. Guidance for Green Construction, issued by Ministry of Construction of the People's Republic of China, defines the concept of green construction, and clears principles, frameworks and points of green construction. It guides the construction projects and others for reference. The green construction is divided into six parts in the code, construction management, environmental protection, material-saving and material utilization, water-saving and water resources utilization, energy-saving and energy utilization, and land-saving and land resources utilization.

Evaluation Standard for Green Construction of Building. Evaluation Standard for Green Construction of Building, GB/T 50640-2010, combines the construction management with the "four conversations and one protection", and divides the construction project evaluation into three stages, foundation engineering, main structural engineering, and decoration and electromechanical fixing engineering. Each stage is evaluated according to the five evaluation elements, and then evaluation index and methods are proposed. Every evaluation elements consists of prerequisite item, general item and extra item. Prerequisite item is compulsory and general item scores while extra item adds marks according to whether measures are right. Finally, the unit project's score can be gotten with a certain weight, and thus, the level of green construction can be determined.

Technical Index for Green Construction of Technological Demonstration Project. Technical Index for Green Construction of Technological Demonstration Project, issued by Ministry of Housing and Urban-Rural Development of the People's Republic of China, divides green construction into seven parts, in addition to the six parts in the first code, technological innovation and technological utilization is included. This code is used to evaluate the technology demonstration project of green construction in construction projects, and contains 13 quantifiably control values and 87 technical indexes (include 56 prerequisite items). When quantifiably control values and prerequisite items are totally satisfied, and others' coincidence rate is more than $70 \%$, the project will be passed.

Current Problems. The three codes have the same objectives and core contents, and there are many repetitions between the terms in different codes. However, the differences of emphasis, framework and scoring standards make it difficult to have a uniform evaluation. Certain evaluation results can't be used for other evaluation codes, a re-evaluation should be done in accordance with the 
requirements of the new evaluation code, which results in lots of repetitive work. In a sense, it is a waste of labor resources, and don't meet the concept of green construction. However, research in this aspect is blank.

\section{Informatization and Green Construction}

Construction Project Informatization. With the arrival of the information age, the construction industry has taken enormous changes. The project methods and means have been improved, and the idea and organization of engineering management has also been transformed and innovated. While the quality is improved, the cost is also controlled. The concept of construction project informatization comes into being. This is to say, construction project informatization is a multi-level technological tool from the single function to technological integration, from the single-chip application to the network interaction by replacing the traditional way with developed and utilized Internet. And standardized management, resources saving, environmental protection and other purposes come true [13].

In the traditional information communication shown in Figure 1(a) [14], 70\% information communication will be wrong, resulting $3 \%$ to $5 \%$ claims in engineering change, and about $30 \%$ cost increased as well. Making BIM as the center of the communication model shown in Figure 1(b) can make best of BIM, such as visualization, synergy and simulation through the development and application of the relevant software. At the same time, faced with delivery problems between different information format, this paper presents an online efficient collaborative model shown in Figure 1(c), which puts database platform as the core of information integration, retains the advantages of BIM, and gives a way to solve the drawback of BIM in application.

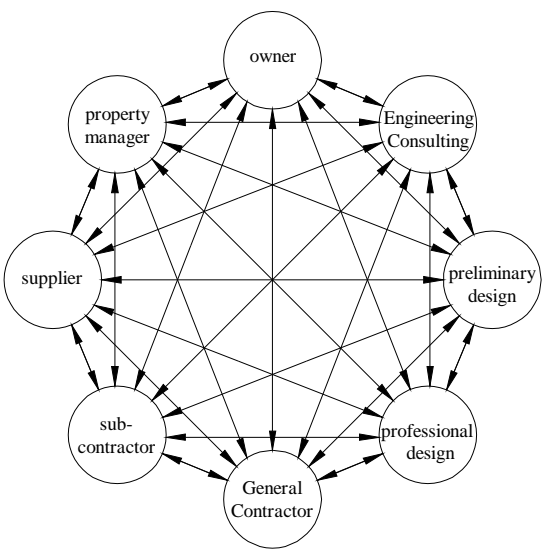

(a) Traditional Model

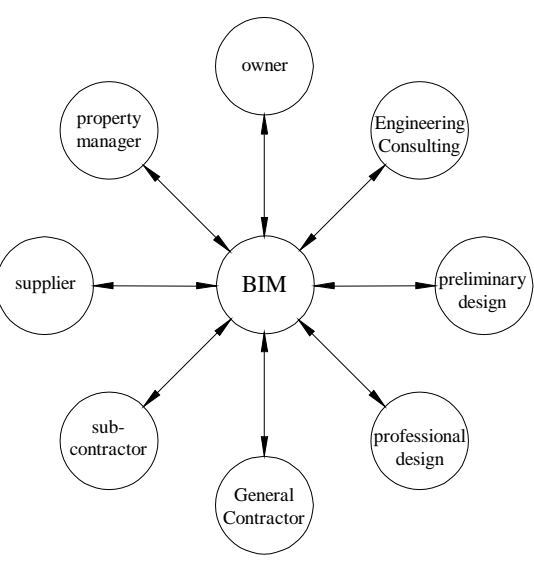

(b) Based on BIM

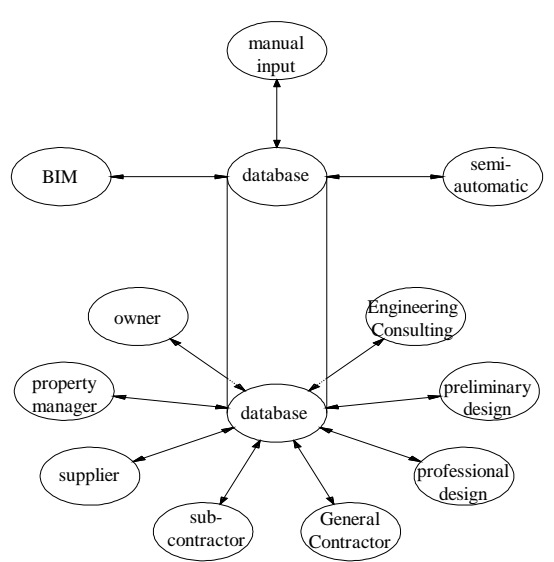

(c) Based on Database

Fig.1 Information Exchange Model

Analysis on Green Construction Evaluation Indexes. Green construction evaluation index which is part of construction project information, has the similar characteristics as shown in Table 1. To ensure the standardization and rationality of the green construction evaluation index system, the green construction evaluation platform proposed should meet the demands of integrity, systematism, uniqueness, remote management and interactivity.

Integrity. The construction index system of green construction should be detailed and comprehensive, and cover all terms of Guidance for Green Construction, Evaluation Standard for Green Construction of Building and Technical Index for Green Construction of Technological Demonstration Project.

Systematism. Each code has a self-contained system, making it difficult to conclude a uniform construction evaluation. By integrating all terms in the three codes, a complete evaluation system is established. During a process, the evaluation of all terms will be done, and results can be output as required. 
Table.1 Characteristics of Green Evaluation Index

\begin{tabular}{|c|c|c|}
\hline Construction Project Information & Green Evaluation Index & Management \\
\hline 1. Large amount of information & 1. The number of indicators is huge & \\
\hline 2. The information type is complex & 2. Many types of indicators & \\
\hline $\begin{array}{l}\text { 3. Wide range of information, and } \\
\text { scattered storage }\end{array}$ & 3. Scattered storage & $\begin{array}{l}\text { 1. Integrity } \\
\text { 2. Systematism }\end{array}$ \\
\hline 4. Dynamic changes & $\begin{array}{l}\text { 4. Checking for improvement several } \\
\text { times }\end{array}$ & $\begin{array}{l}\text { 3. Uniqueness } \\
\text { 4. Remote Management }\end{array}$ \\
\hline $\begin{array}{l}\text { 5. The application environment is } \\
\text { complex }\end{array}$ & 5. Multi - index system & 5. Interactivity \\
\hline 6. Systematism & 6. Systematism & \\
\hline
\end{tabular}

Uniqueness. The evaluation index is the only criterion for the green construction evaluation, and the accuracy and simplicity of the information should be ensured. The same information in the three terms should be merged, and be coded according to specified rules to make is sure that the coding and information are one-to-one correspondence.

Remote Management. Green construction is a huge system engineering, involving government, owners, construction and many other subjects. The propossed green construction evaluation platform should be timely and convenient. And users can add, delete, modify and view information through computer or smartphone at any time.

Interactivity. The information exported from BIM model is imported into the green construction evaluation platform, and it can directly determine the relevant green construction evaluation index, greatly improving the efficiency. Then the results from the green construction evaluation platform are, imported into the database, so that other users can have a quickly access to the construction evaluation information.

\section{Green Construction Evaluation Based on Information Technology}

Codes Decomposition. The three evaluation codes are completed using different frameworks, there is something repetitive in the three codes. To make the three evaluation codes can be unified in an evaluation process, and achieve the goal of "one evaluation, and three kinds of outputs", firstly, the three evaluation terms need to be analyzed. Secondly, the repetitive or hierarchical sentences should be broken up on the premise of maintaining the integrity of other original terms in the process. Through analysis and decomposition, 363 sentences are gotten. Lastly, the 363 sentences accordance with a specified logical relationship will be put into seven chapters, construction management, environmental protection, materials saving and utilization, water saving and utilization, energy saving and utilization, land saving and protection, and technological innovation and utilization, each chapter has five levels according to needs.

Coding System. Coding is the only identification of each sentence. To achieve the goals of "one evaluation, and three kinds of outputs", and sort sentences in accordance with the framework of the above three codes, coding should meet the following four conditions: 1) can uniquely determine the chapter number that sentences belongs to, 2) can uniquely determine the position of the statement in the structure level, 3) can uniquely determine the code of the sentences, and indicate the numbering of the terms, and 4) can uniquely determine the way to evaluate of each sentence. Therefore, the proposed coding system consists of four parts, chapter number, structure level, terms numbering and data type. The coding scheme is shown in Figure 2. 


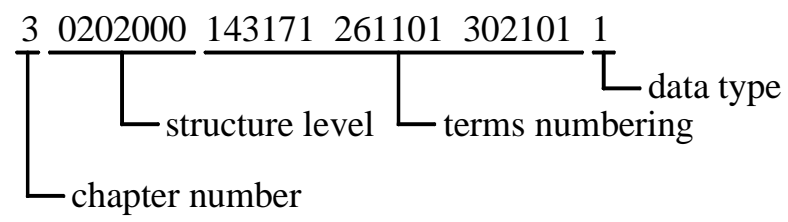

Fig. 2 Coding

The chapter number consists of a 1-bit code. "3" represents Chapter 3, material and material utilization. The structure level consists of a 7-bit code, the first two bits indicate the location of the first layer, the second two bits indicate the location of the second layer, and the last three bits indicate the location of the third layer, fourth layer and fifth layer. "0202000" represents that the sentence is located at the second one of the sub-layer which is the second one of the first layer. Each code is composed of a 6-bit code, the first bit indicates the code, the next 4 bits indicate the numbering of the term, and the last one indicates the position of the specific term. Taking the ability to sort any codes individually into consideration, the three evaluation codes should be coded side by side, so the terms numbering consists of an 18-bit code. "143171" represents that the sentence is the first part of the Guidance for Green Construction 4.3.1.7, "261101" represents that the sentence belongs to the first part of Evaluation Standard for Green Construction of Building 6.1.1, "302101" represents that the sentence belongs to the first part of Technical Index for Green Construction of Technological Demonstration Project 0.2.1. Finally, data type consists of 1-bit code. "1" indicates that the sentence need to be determined, and "2" indicates the need for specific data.

Scoring System. The three codes have different scoring methods as shown in Table 2. To achieve "one evaluation, and three kinds of output", the scoring method also needs to be unified. Through analysis, two scoring methods are needed. One for the indexes without of specific value, the coincidence degree of which needs to be determined humanly. The other one with specific numerical indexes, which only need to fill in specific value, and the platform will judge automatically. The two scoring methods correspond respectively to the data type "1" and "2" of coding system. The evaluation process is shown in Figure 3.

Table.2 The standard scoring method

\begin{tabular}{|c|c|c|}
\hline \multicolumn{2}{|c|}{ Evaluation Codes } & Evaluation Methods \\
\hline Guidance for Green Construction & items & Compatible or incompatible \\
\hline & prerequisite item & Compatible or incompatible \\
\hline Evaluatlon Standard for Green & general item & 2 points, 1 points or 0 points \\
\hline Constructıon of Bullding & extra item & 1 points, 0.5 points, or 0 points \\
\hline Technical Index for Green & quantifiably control values & specific value \\
\hline $\begin{array}{c}\text { Construction of Technological } \\
\text { Demonstration Project }\end{array}$ & technical indexes & Compatible or incompatible \\
\hline
\end{tabular}

Sentences Basis Scores $\quad-$ Terms Basis Scores $\quad-$ Terms Conversion Scores $\quad$ Evaluation Results

Fig.3 Evaluation process

Sentences Basis Scores. For the first case, the scoring method of the Evaluation Standard for Green Construction of Building's general item is general, through value conversion the scores of other items are gotten. Therefore, this evaluation method can be used to get the basic score of each sentence. If measures are taken in place and evaluation indexes are met totally, scores 2 points. If measures are taken in place and evaluation indexes are met partly, scores 1 points. If measures are not taken in place and evaluation indexes are not met, scores 0 points. For the second case, if the required indicators are satisfied, scores 2 points, if not scores 0 points.

Terms Basis Scores. The terms of the evaluation codes are broken down into many sentences, it is necessary to transform sentences basis scores to terms basis scores. If each sentence of the term gets 2 
points, then this term scores 2 points. If each sentence of the term gets 0 points, then this term scores 0 points. And others score 1 point.

Terms Conversion Scores. The terms evaluation is not same in the three codes, and the terms basis scores need to be converted in accordance with specific rules. For Guidance for Green Construction, Evaluation Standard for Green Construction of Building's prerequisite item, Technical Index for Green Construction of Technological Demonstration Project, if the terms basis scores score of 1 or 2 points, it meets the requirements, otherwise does not meet the requirements. For Evaluation Standard for Green Construction of Building's general item, the same as terms basis scores. For Evaluation Standard for Green Construction of Building's extra item, it equals to the terms basis scores multiplied by 0.5 .

Evaluation Results. The evaluation process after gaining terms conversion scores is the same as the general evaluation process. The evaluation results are obtained according to the evaluation methods.

\section{Conclusions}

The evaluation results obtained by green construction evaluation platform are fully matched with the existing standard and can be used directly in the green construction evaluation activities, which greatly improves the efficiency and saves the labor resources. To further optimize green construction evaluation platform, the next step is as follows:

1) Certain terms are only useful under certain circumstances, so "excluding this clause" can be increased in the score options.

2) Combine key points with norms to make it possible for people concerned to compare after seeking.

3) Something similar in the three norms can be associated with coding criterion so that it can be automatically converted when output.

4) Add coding to foundation and basic engineering, structural engineering, decoration and electromechanical installation engineering distinguish the unit projects.

5) Further study the link between BIM and the green construction evaluation clause so as to simplify the evaluation process.

\section{References}

[1] Liang Bian. Green Construction Assessment Based on the Multilevel Extension Method [D] (in Chinese). Lanzhou University of Technology, 2016.

[2] Ministry of Construction of the People's Republic of China. Guidance for Green Construction [S] (in Chinese). http://www.gov.cn, 2007.

[3] Ministry of Housing and Urban-Rural Development of the People's Republic of China. GB/T 50640-2010 Evaluation Standard for Green Construction of Building[S] (in Chinese). Beijing: China Planning Press, 2011.

[4] Xiaohong Chen. Green Construction Assessment Based on AHP Method[J] (in Chinese). Construction Technology, 2006, (11): 85-89.

[5] Wanqing Li, Mujie Chen, Wenqing Meng. The Fuzzy Comprehensive Evaluation of Green Construction Based on the Improved Membership Transformation Algorithm[J]. Scientific Decision Making, 2011.

[6] HuiLing Li, Jun Li, Qin Zhong. Green Construction Evaluation Based on Grey Clustering Method[J] (in Chinese). Journal of Engineering Management, 2012, (02): 18-22.

[7] Zaixing Liu. Fuzzy and Comprehensive Evaluation of Green Construction Based on BP Artificial Neural Network[J]. Value Engineering, 2015.

[8] Yingpan Li, Xiaofei Ma, Xin Liang, et al. Research on Information Management of Green Construction Based on Cloud-BIM[J]. Construction Technology, 2016. 
[9] UK. BREEAM (Building Research Establishment Environmental Assessment Method). http://www.bre.co.uk, 2004.

[10] The leadership in energy and environmental design. Green Building Rating System TM2.0[M]. New York: The US Green Building Council, 2001.

[11] Dan Li. Research on Green Construction Evaluation System for Construction Engineering[D] (in Chinese). Beijing Jiaotong University, 2015.

[12] Ministry of Housing and Urban-Rural Development of the People's Republic of China. Technical Index for Green Construction of Technological Demonstration Project [S] (in Chinese). Beijing: Housing and Urban and Rural Construction Department of building energy efficiency and technology companies, 2013.

[13] YongGang Liu, Yungan Xuan. Construction Engineering Informatization and Life Cycle Management[C] (in Chinese). National Engineering Construction Computer Application Conference, 2006: 5.

[14] Shizhao Ding. Introduction to Construction Project Informatization[M] (in Chinese). China Architecture \& Building Press, 2005. 